\title{
ANÁLISE MORFOLÓGICA DO APARELHO UNGUEAL DO VEADO-CATINGUEIRO (Mazama gouazoubira, Fischer, 1814) (Artiodactyla, Cervidae)
}

\author{
Lorenna Cardoso Rezende ${ }^{1}$, Juliana Passos Alves dos SAntos $^{2}$, LuCAS Tarago URbani ${ }^{3}$, \\ Alvaro CARlos Galdos-Riveros ${ }^{4}$, MARIA ANGELICA MigLinO ${ }^{5}$ \\ ${ }^{1}$ Professora Doutora da Universidade de Brasília, Brasília, DF, Brasil. lorisvete@ yahoo.com.br. \\ ${ }^{2}$ Doutora pela Universidade de São Paulo, São Paulo, SP, Brasil. \\ ${ }^{3}$ Graduando em Medicina Veterinária pela Universidade de São Paulo, São Paulo, SP, Brasil. \\ ${ }^{4}$ Doutor pela Universidade de São Paulo, São Paulo, SP, Brasil. \\ ${ }^{5}$ Professora Doutora da Universidade de São Paulo, São Paulo, SP, Brasil.
}

\begin{abstract}
A espécie estudada neste trabalho é conhecida como veado-catingueiro. Dois cervídeos adultos do Mazama gouazoubira (Fischer, 1814), doados ao laboratório de Anatomia dos Animais Domésticos e Silvestres da Faculdade de Medicina Veterinária e Zootecnia da Universidade de São Paulo, foram conservados em formaldeído (10\%). As úngulas ou casco são em número de quatro em cada membro e protegem a extremidade distal do membro, revestindo a falange distal. O ângulo dos cascos foi aferido e as amostras dos dígitos foram processadas para microscopia de luz e eletrônica de varredura. Na macroscopia, o comprimento da parede dorsal do casco mediu aproximadamente $2,5 \mathrm{~cm}$; o ângulo
\end{abstract}

formado na pisada foi de $35^{\circ}$ para o membro torácico e $33^{\circ}$ para o membro pélvico. Na microscopia foi possível visualizar o estrato externo como uma camada muita fina $(141,5 \mu \mathrm{m})$; o estrato médio, constituído por queratina tubular pigmentada, que é a principal estrutura de sustentação da parede do casco, e o estrato interno contendo lâminas distribuídas de forma longitudinal e paralela, importante para unir a parede do casco com a superfície dorsal e lateral da falange distal. Os dados obtidos do aparelho ungueal dos cervídeos estudados podem auxiliar na elucidação do crescimento e identificação das pegadas dos mesmos.

PALAVRAS-CHAVE: casco; cervídeo; falange distal; rastros.

\section{MORPHOLOGICAL EVALUATION OF THE UNGULA APPARATUS OF THE GRAY BROCKET DEER (Mazama gouazoubira, Fischer, 1814) (Artiodactyla, Cervidae)}

\section{ABSTRACT}

The species studied in this research is known as gray brocketdeer. Two Mazama gouazoubira (Fischer, 1814) adult exemplars, donated to the Laboratory of Anatomy of Domestic and Wild Animals, Faculty of Veterinary Medicine, São Paulo University, were preserved in formaldehyde $(10 \%)$. There are four ungulas or hulls on each member and they protect the distal end of the limb, covering the distal phalanx. The angle of the hoof was measured and samples of the digits were processed for light microscopy and scanning electron microscopy. In macroscopy, the length of the dorsal wall of the hoof measured approximately $2.5 \mathrm{~cm}$, the angle formed at the step was $35^{\circ}$ for the forelimb and $33^{\circ}$ for the hindlimb. In microscopy, we could visualize the outer stratum as a very thin layer $(141.5 \mu \mathrm{m})$, the middle stratum, composed of keratin tubular pigment, which is the main support structure of the wall of the hull, and the inner layer containing parallel slides in a longitudinal distribution, which is important to connect the hoof wall to the dorsal and lateral surface of the distal phalanx. The data from the ungular apparatus of the deers studied may help to elucidate the growth and identification of the footprints of these animals.

KEYWORDS: deer; distal phalanx; hoof; tracks. 


\section{INTRODUÇÃO}

Os cervídeos, família Cervidae, pertencem à ordem Artiodactyla, constituindo uma ordem de animais mamíferos ungulados com um número par de dedos nas patas e caracterizados, também, pela presença de cascos que recobrem totalmente os quatro dedos (MORO-RIOS et al., 2008). Os Artiodactilos têm extremidades especializadas tanto para força como para velocidade (KARDONG, 2007).

No mundo, existem 17 gêneros e 45 espécies de cervídeos (WALKER, 1991), distribuídos na América, Europa, Ásia e norte da África. Eles tiveram uma rápida radiação adaptativa durante o Pleistoceno (aproximadamente 2.500 .000 anos) na América do Sul, chegando a ocupar nichos ecológicos que, em outros continentes, como a África, estão ocupados pelos bovídeos (REDFORD \& EISENBERG, 1992).

A diversidade de ambientes ocupados pode influir em aspectos de sua ecologia, como seleção de habitat, dieta, reprodução, e no comportamento social dos indivíduos. Esses animais apresentam, geralmente, comprimento variando de 0,91 a $1,0 \mathrm{~m}$, altura da cernelha de 35 a $65 \mathrm{~cm}$ e peso entre $13 \mathrm{e}$ $20,5 \mathrm{~kg}$ (PINDER \& LEEUWENBERG, 1997). Esse animal se alimenta de grande variedade de plantas, sendo considerado um animal frugívoro e seletivo (BODMER, 1991; BLACK \& VOGLIOTTI, 2008).

O casco constitui-se de lâminas grossas queratinizadas situadas sobre o extremo dos dedos dos ungulados, sem vasos sanguíneos nem nervos, similar a outras estruturas derivadas da epiderme como a unha, os cornos e as garras. Ele tem como função dar suporte e distribuir, assim como amortecer o peso do animal, absorver impacto que representa o apoio do corpo no solo e permitir a locomoção (ACUÑA et al., 2004).

O casco é composto por duas partes, um epitélio superficial (epiderme) e uma camada fibrosa resistente (derme), que repousa em um estrato de tecido conjuntivo frouxo (subcutâneo). A epiderme é queratinizada e a derme é uma estrutura altamente vascularizada que tem como função a nutrição e inervação do casco. Por último, o tecido subcutâneo que forma a almofada digital (STUMP, 1967; HOOD, 1999).

A unha dos ungulados cresce a partir de uma prega curva da derme na coroa do casco. A epiderme abaixo da maior parte da unha produz um tecido córneo que mantém a adesão à medida que a unha desliza gradualmente no sentido distal. A derme sobre a epiderme reúne-se em algumas pregas longitudinais baixas (lâminas), que se interdigitam com as lâminas epidérmicas correspondentes; o contato dermoepidérmico ampliado acentua a ligação entre a unha e os tecidos mais profundos (DYCE et al., 2010).

A epiderme divide-se em: estrato basal, estrato germinativo e estrato córneo. $\mathrm{O}$ estrato córneo ainda se subdivide em: estrato externo, estrato médio e estrato interno ou lamelar. Este último é constituído por lamelas paralelas, distribuídas de forma longitudinal, formando um tecido queratinoso, sendo importante para unir a parede da muralha e a superfície dorso lateral da estrutura óssea (KONIG \& LIEBICH, 2004).

A camada germinativa da epiderme e o córion têm uma íntima relação, por consequência, qualquer lesão numa dessas estruturas conduz a prejuízos na outra. A estabilidade estrutural do tecido córneo é resultante dos complexos formados entre a queratina e aminoácidos (COLLINS et al., 2010).

Quanto à constituição óssea, cada dedo é formado por três ossos principais: falange proximal; falange média; e falange distal. $\mathrm{O}$ osso mais susceptível de ser lesado é a falange distal, pois está mais exposto a traumatismos ou a agentes infecciosos que podem chegar até ela após a ocorrência de lesões e deformações na proteção córnea ou epiderme. A parte distal da falange média e a falange distal são recobertas em quase sua totalidade pelo tecido conjuntivo subcutâneo (ACUÑA et al., 2004).

A forma do casco deve ser compatível com a conformação e o peso corporal do animal. Eles devem ser arredondados, de tamanho grande, sem apresentarem talões estreitos. O crescimento do casco do cervídeo é de $0,5 \mathrm{~cm}$ por mês (MILLER et al., 1986).

Até o momento não existem relatos na literatura sobre a conformação da extremidade distal dos membros de cervídeos. Portanto, o estudo das camadas componentes do casco desses animais pode auxiliar na elucidação do seu crescimento, identificação de suas pegadas e em procedimentos cirúrgicos no Mazama gouazoubira (Fischer, 1814).

\section{MATERIAL E MÉTODOS}

Análises macroscópicas e microscópicas dos cascos foram realizadas em dois cervídeos Mazama gouazoubira (Fischer, 1814) adultos pertencentes ao 
acervo do laboratório de Anatomia dos Animais Domésticos e Silvestres da Faculdade de Medicina Veterinária e Zootecnia da Universidade de São Paulo. Os espécimes estavam conservados em solução de formaldeído (10\%). Aferiu-se o ângulo do casco entre a parede dorsal do casco e a superfície solear, sendo medido na região da pinça, conforme descrito por BALCH et al. (1997).

Após a biometria, amostras dos dedos III e IV foram coletadas em secções transversais, com cortes paralelos à borda da sola do casco, e longitudinais na região que abarcou o períoplo até a sola do casco. O material foi processado pelas técnicas microscópicas de histologia de luz e eletrônica de varredura (MEV). Para histologia, a espessura dos cortes foi de $3 \mu \mathrm{m}$ e o material foi corado com Hematoxilina-Eosina (HE). Para a microscopia eletrônica de varredura (MEV), as amostras foram cobertas com ouro (coloidal) e examinadas em microscópio Carl Zeiss (DSM 940A) e LEO (435 VP).

\section{RESULTADOS}

A extremidade distal dos membros do cervídeo da espécie $M$. gouazoubira consiste do carpo ou tarso estendendo-se até as falanges dos dedos que são separados em dígitos mediais e laterais, por serem animais ungulígrados.

As úngulas ou casco são em número de quatro em cada membro e protegem a sua extremidade distal, cobrindo a falange distal. O casco do dígito principal acompanha o formato da falange distal, possuindo três superfícies: a parede abaxial, a parede interdigital e a sola. Os dígitos acessórios são compostos por falanges vestigiais nodulares cobertas por curtas cápsulas córneas cônicas, que se assemelham às dos dígitos principais (Figuras 1A, 1B).

Macroscopicamente, o dígito lateral do membro pélvico é maior por suportar mais peso (Figura 1C), ocorrendo o inverso no membro torácico.

A parede abaxial do casco cobre cranial e lateralmente a falange distal e reflete-se em ângulo agudo na direção palmar ou plantar. $\mathrm{O}$ formato do estojo córneo é convexo lateralmente e marcado por cristas paralelas na borda coronal na zona de crescimento do casco (Figura 1). Próximo à junção do casco com a pele, uma faixa de tecido queratinizado macio, identificado como períoplo
(Figuras 1A, 1B), repousa sobre a superfície externa da parede do casco, sendo que, com o crescimento do casco, esse tecido seca, tornado-se uma camada lustrosa protetora recobrindo toda a parede do casco.

A superfície palmar ou plantar é formada pela borda distal da parede do estojo córneo, sola e bulbo. No animal em estação, observamos lateralmente a parede (Figuras 1A, 1B) e, caudalmente, o bulbo (Figura 1C). O comprimento da parede dorsal do casco mediu aproximadamente $2,5 \mathrm{~cm}$ (Figura 1D). A média dos ângulos do casco no membro torácico foi $35^{\circ}$ e no membro pélvico foi $33^{\circ}$ (Figura 2).

$\mathrm{Na}$ microscopia eletrônica de varredura (MEV), foi possível visualizar a morfologia de todas as camadas que compõem a extremidade distal do membro (Figura 3). O casco é formado pela queratinização do epitélio sobre uma derme bastante modificada, dividido em estrato externo, médio e interno. $\mathrm{O}$ estrato externo apresentou uma camada muito fina e recobriu a superfície externa da parede com espessura média de 141,5 $\mu \mathrm{m}$ (Figuras 3A, 3B, 3C, 3D). A epiderme de revestimento dessas papilas produz túbulos córneos que correm distalmente em direção à margem de sustentação do peso da parede. Os túbulos estão incrustados em tecido córneo intertubular menos estruturado, formado pela epiderme sobre as regiões interpapilares da derme; a combinação de tipos de tecido córneo confere ao tecido um aspecto finamente estriado (Figura 3B).

$\mathrm{O}$ estrato médio é constituído de queratina tubular pigmentada (Figura 3A), observada como bandas sobrepostas na microscopia óptica (Figura 3B), sendo que esses túbulos córneos são melhor observados no corte transversal na MEV (Figura 3F), sendo a principal estrutura de sustentação da parede do casco.

Em contrapartida, o estrato interno é uma camada não pigmentada (Figuras 3A), composto por várias lâminas epidérmicas e dérmicas, distribuídas de forma longitudinal e paralela, observadas na MEV (Figuras 3H, 3I) com muitos vasos sanguíneos com formato arredondado, distribuídos entre essas lâminas (Figuras 3D, 3E, 3F). Essas lâminas são formadas por tecido queratinoso, cuja importância reside na união da parede do casco com a superfície do periósteo da falange distal (Figuras $3 \mathrm{H}$ e 3I). A união entre as lâminas epidérmicas e dérmicas permite à parede deslizar gradualmente em direção ao solo, onde sua borda distal é gasta. 


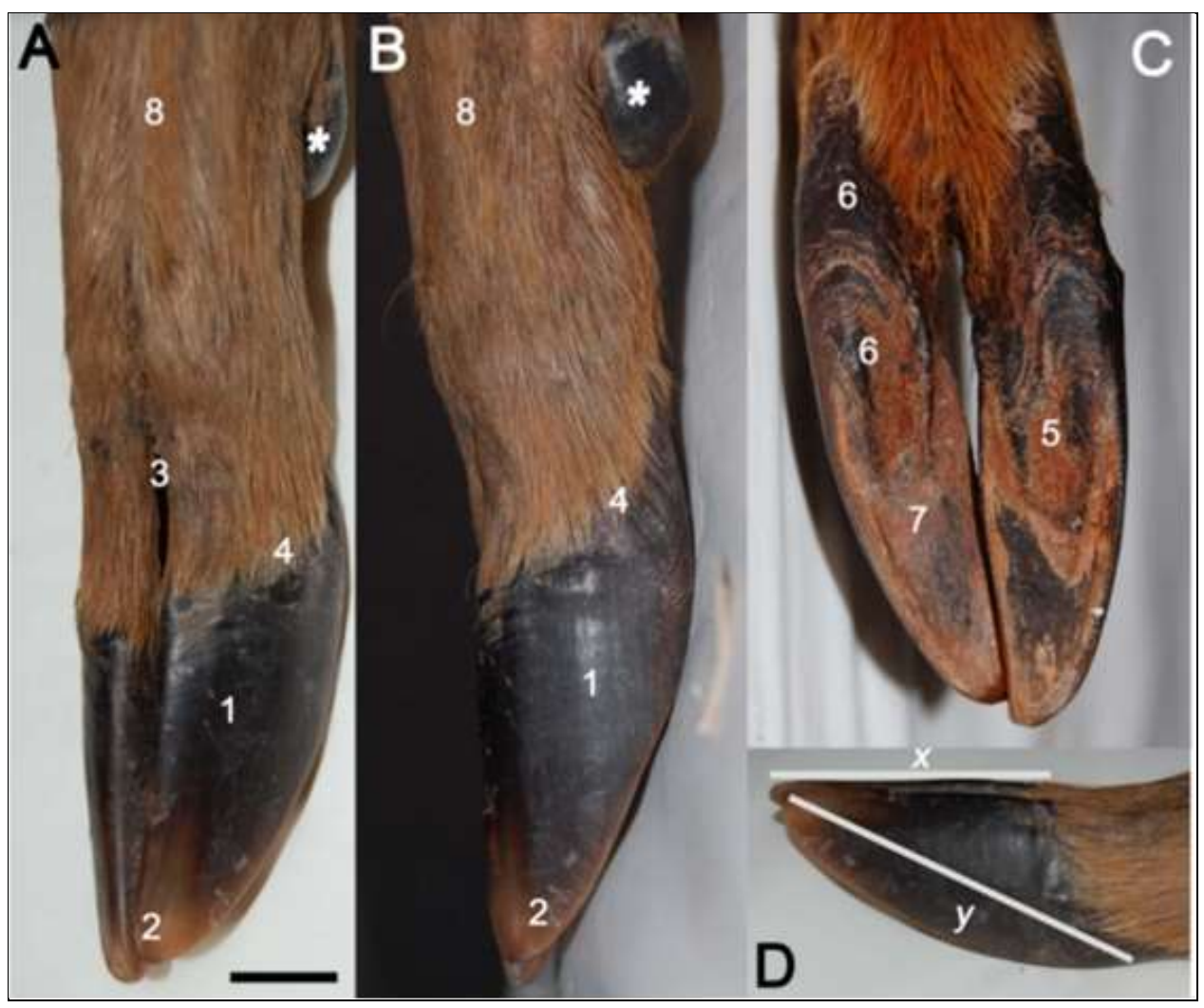

Figura 1- Vista dorsal (A), lateral (B, D) e plantar (C) da extremidade do membro pélvico direito do Mazama gouazoubira. Observar: parede do casco (1); pinça (2); comissura interdigital (3); região do períoplo (4); sulco axial (5); bulbo (6); sola (7); casco do dedo rudimentar (*); metatarso (8); parede dorsal do casco (linha $\mathrm{x}$ ) e parede diagonal do casco (linha y). Barra: $1 \mathrm{~cm}$.

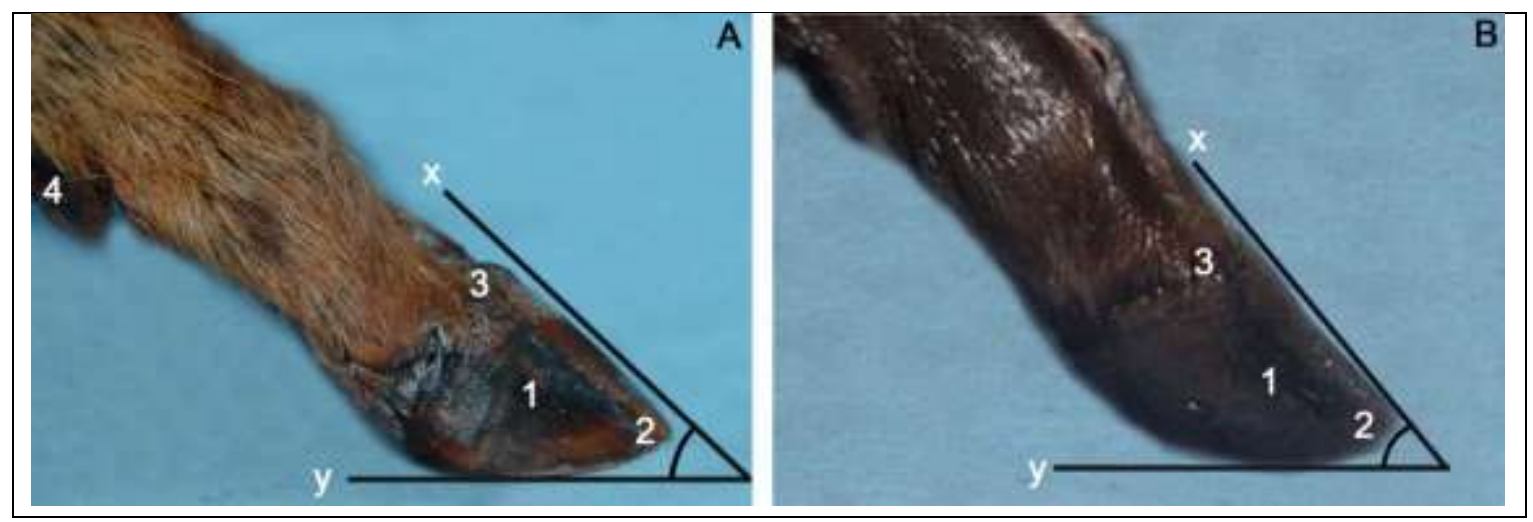

Figura 2- Vista lateral da extremidade do membro pélvico direito (A) e torácico (B) esquematizando o ângulo do casco do Mazama gouazoubira. Observar: parede do casco (1); pinça (2); comissura interdigital (3); casco do dedo rudimentar (4); linha paralela à parede dorsal do casco (x) e linha paralela à sola do casco (y). 


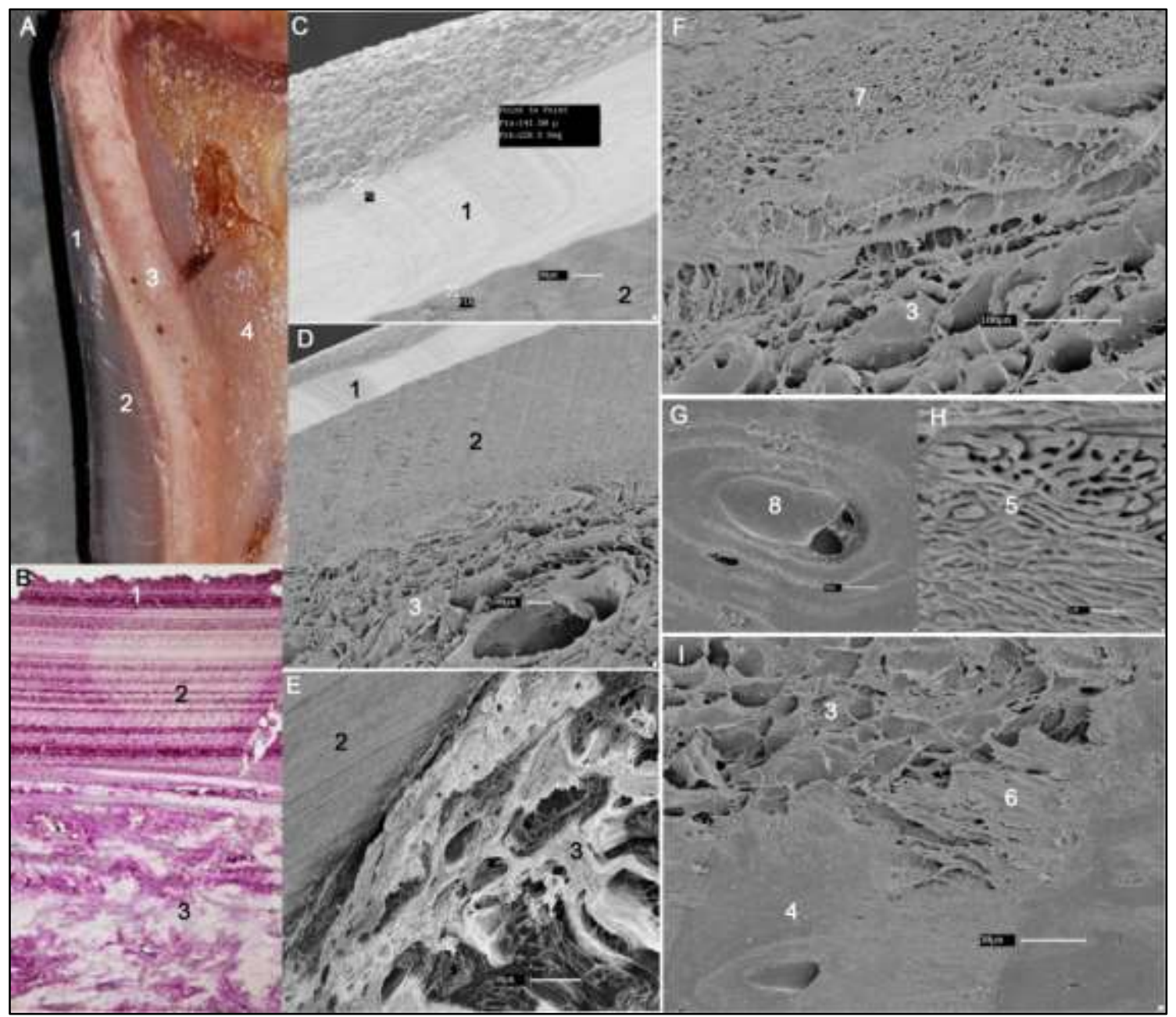

Figura 3 - Estrutura da parede do casco, derme laminar subjacente e falange distal do Mazama gouazoubira. (A) imagem macroscópica do corte longitudinal do casco, (B) imagem histológica do corte longitudinal, HE40x, (C-I) MEV. Observar: estrato externo da parede do casco - períoplo seco (1); estrato médio da parede consistindo em túbulos córneos embutidos em intertúbulos córneos menos estruturados (2); derme laminar (3); falange distal (4); lâminas dérmicas (5); lâminas dérmicas presas no periósteo (6); corte transversal dos túbulos córneos (7); canal central (8). Barra: $1 \mu \mathrm{m}(\mathrm{H}), 10 \mu \mathrm{m}(\mathrm{G}), 30 \mu \mathrm{m}$ (C,E,I), $100 \mu \mathrm{m}(\mathrm{D}, \mathrm{F})$.

\section{DISCUSSÃO}

Os ungulados apoiam o corpo apenas na última falange dos dedos, que é protegida por um estojo córneo. Portanto, o casco é uma especialização epidérmica que protege a extremidade distal do membro. O conhecimento da disposição dos tecidos componentes desse anexo cutâneo auxilia na identificação das pegadas do $M$. gouazoubira, além de possibilitar intervenções cirúrgicas e correções na angulação dos cascos desses animais.

A sola entre o bulbo e a parede é pequena no
M. gouazoubira, como também descrito para os ruminantes e suínos (DYCE et al., 2010). A espécie M. gouazoubira possui como característica de rastro marcas comprimidas lateralmente. A impressão de cada dígito é alargada na margem posterior (de borda convexa), estreitando-se para a margem anterior, a qual termina em uma unha pontuda. É difícil e pouco confiável a distinção entre os rastros dessa espécie e de outras espécies de veados de pequeno porte (MORO-RIOS et al., 2008).

Foi preconizado para uma postura adequada que os dois ângulos das pinças dos cascos de um 
membro sejam iguais, frisando-se que existe alta correlação entre alterações do ângulo de pinça e comprimento da face dorsal com ocorrência de lesões podais (CABRAL et al., 2004). A angulação da pisada do membro torácico foi menor para o $M$. gouazoubira quando comparado com os equinos e bovinos, que apresentam aproximadamente $50^{\circ}$ a $55^{\circ}$ (ANDRADE, 1986).

Quando o interesse maior é obter informações topográficas, o MEV é o instrumento mais versátil para avaliação, exame e análise das características microestruturais (DYKSTRA, 1993), permitindo analisar a disposição do tecido epitelial, conjuntivo e ósseo, como por exemplo, a disposição das lâminas interdigitais que são menos desenvolvidas no $M$. gouazoubira, como também descrito para os ruminantes e suínos, quando comparadas com os equinos (DYCE et al., 2010).

Há uma vasta literatura descrevendo o casco de bovinos (DYCE et al., 2010) e equinos (KUWANO, 1996; COLLINS et al., 2010); entretanto, os relatos sobre cervídeos são escassos. Considerando a importância dessa estrutura anatômica no sistema locomotor, estudos adicionais são necessários. Até o presente momento, não foram relatados estudos quanto à estrutura e ultraestrutura ungueal desses animais; portanto, os dados obtidos neste trabalho poderão auxiliar na descrição da extremidade distal dos membros torácicos e pélvicos e sua possível correlação com outros animais silvestres ou domésticos.

Em relação às estruturas encontradas na MEV do casco do cervídeo, pode-se observar a disposição das lâminas epidérmicas e dérmicas, dos vasos sanguíneos imersos no estrato interno da derme, além da relação dos tecidos epitelial, conjuntivo e ósseo que compõem a extremidade distal do membro. Podemos concluir em relação à angulação dos cascos que houve uma grande diferença com relação aos bovinos e equinos (KUWANO, 1996; COLLINS et al., 2010), o que era esperado devido à postura corporal e hábitos de vida dos cervídeos, que são animais mais leves; por outro lado, mais estudos sobre a anatomia da locomoção desses animais são necessários para um melhor entendimento e aplicação na área clínica e cirúrgica.

\section{REFERÊNCIAS}

ACUÑA, R.; ALZA, D. H. Cojeras del bovino: fisiopatologia y profilaxis. Buenos Aires: Intermédica Editorial, 2004. 139 ISBN 9789505552719.

ANDRADE, L. S. O condicionamento do cavalo no Brasil - trabalho, competição, reprodução. Recife: Art 3, 1986. 201 p.
BALCH, O. K.; BUTLER, D.; COLLIER, M. A. Balancing the normal foot: hoof preparation, shoe fit and shoe modification in the performance horse. Equine Veterinary Education, v.9, p.143-154, 1997.

BLACK, P.; VOGLIOTTI, A. IUCN Red List of Threatened Species. 2008. Acesso em: 14 Outubro. Disponível

<http://www.iucnredlist.org/details/29620/0>

em:

BODMER, R. E. Influence of digestive morphology on resource partitioning in Amazonian ungulates. Oecologia, v. 85, p. 361-365, 1991.

CABRAL, G. C.; ALMEIDA, F. K.; AZEVEDO, P. C. N.; QUIRINO, C. N.; SANTOS, E. M.; CORASSA, A.; PINTO, L. F. B. Avaliação morfométrica de equiinos da raça Mangalarga Marchador: medidas angulares. Revista Brasileira de Zootecnia, v. 33, p. 1790-1797, 2004. ISSN 1516-3598. Disponível em: http://www.scielo.br/scielo.php?script=sci _arttext\&pid=S1516-35982004000700017\&nrm=iso >.

COLLINS, S. N. VAN EPS, A. W.; POLlITT, C. C.; KUWANO, A. The Lamellar Wedge. The Veterinary clinics of North America. Equine practice, v. 26, n. 1, p. 179-195, 2010. ISSN 0749-0739. Disponível em: < http://linkinghub.elsevier.com/retrieve/pii/S07490739100 00052? showall=true $>$.

DYCE, K. M.; SACK, W. O.; WENSING, C. J. G. Tratado de Anatomia Veterinária. 4. Canada: Elsevier, 2010. 872 p.

DYKSTRA, J. A. Manual of applied techniques for biological electron microscopy. 1. ed. New York: Plenum Press, 1993. 257 p.

HOOD, D. M. The pathophysiology of developmental and acute laminitis. The Veterinary Clinics of North America. Equine Pratice, v. 15, p. 321-343, 1999.

KARDONG, K. V. Vertebrados: Anatómia comparada, función $\mathbf{y}$ evolución. 4. Madrid: McGraw-HILL Interamericana, $2007.782 \mathrm{p}$.

KONIG, H. E.; LIEBICH, H. Anatomia dos animais domésticos. 1. ed. Porto Alegre: Artmed, 2004.

KUWANO, A. Stain Characteristics of Thin Ground Sections of Hydrophobic Resin-Embedded Equine Hooves. Journal of Equine Science, v. 7, n. 2, p. 27-34, 1996.

MILLER, K. V.; MARCHINGTON, R. L.; NETTLES, V. C. The growth rate of hooves of white-tailed deer. Journal of Wildlife Diseases, v. 22, p. 129-131, 1986.

MORO-RIOS, R. F.; SILVA-PEREIRA, J. E.; SILVA, P. W.; MOURA-BRITO, M.; NOGAROLLI, D. Manual de rastros da fauna paranaense. Curitiba: Instituto Ambiental do Paraná: 72 p. 2008. Disponível em < http://www.redeprofauna.pr.gov.br/arquivos/File/bibliotec a/ManualRastros_web22XII08.pdf>

PINDER, L.; LEEUWENBERG, F. Veado-Catingueiro (Mazama gouazoubira, Fisher 1814). In: DUARTE, J. M. 
B. (Ed.). Biologia e conservação de cervídeos sul- STUMP, J. E. Anatomy of the normal equine foot, americanos: Blastocerus, Ozotoceros e Mazama. including microscopic features of laminar region. Jaboticabal: FUNEP, 1997. p. 60-68.

Symposium Equine Foot, v. 15, p. 1588-1599, 1967.

REDFORD, K.; EISENBERG, J. F. Mammals of WALKER, E. Mammals of the world. Baltimore and neotropics. Thesouthern cone. Chicago: University of London: JohnHopkins University Press, 1991. 1398 p. Chicago Press, 1992. $431 \mathrm{p}$.

Protocolado em: 08 fev. 2012. Aceito em: 18 fev. 2013. 